\title{
Synthesis and Study of Morphology and Biocompatibility of Xanthan Gum/Titanium Dioxide-Based Polyurethane Elastomers
}

\author{
Shazia Naheed ${ }^{1, *}$, Muhammad Shahid ${ }^{1}$, Rashida Zahoor ${ }^{1}$, Zumaira Siddique ${ }^{1}$, Nasir Rasool ${ }^{1}$, Sajjad Haider ${ }^{2, *}$ (D) \\ and Shaukat Khan ${ }^{3}$ \\ 1 Department of Chemistry, Government College University, Faisalabad 38030, Pakistan; \\ alchemist019021@gmail.com (M.S.); rashidazahoor786@gmail.com (R.Z.); zumairasiddique@gmail.com (Z.S.); \\ nasirrasool@gcuf.edu.pk (N.R.) \\ 2 Chemical Engineering Department, College of Engineering, King Saud University, P.O. Box 800, \\ Riyadh 11421, Saudi Arabia \\ 3 School of Chemical Engineering, Yeungnam University, 280-Daehak-Ro, Gyeongsan 712-749, Korea; \\ shaukat85@yu.ac.kr \\ * Correspondence: shazianaheed@gcuf.edu.pk (S.N.); shaider@ksu.edu.sa (S.H.); Tel.: +92-(312)-9655311 (S.N.)
}

check for updates

Citation: Naheed, S.; Shahid, M.; Zahoor, R.; Siddique, Z.; Rasool, N.; Haider, S.; Khan, S. Synthesis and Study of Morphology and Biocompatibility of Xanthan Gum/Titanium Dioxide-Based Polyurethane Elastomers. Polymers 2021, 13, 3416. https://doi.org/ $10.3390 /$ polym 13193416

Academic Editor: Edina Rusen

Received: 30 August 2021

Accepted: 27 September 2021

Published: 5 October 2021

Publisher's Note: MDPI stays neutra with regard to jurisdictional claims in published maps and institutional affiliations.

Copyright: (C) 2021 by the authors Licensee MDPI, Basel, Switzerland. This article is an open access article distributed under the terms and conditions of the Creative Commons Attribution (CC BY) license (https:// creativecommons.org/licenses/by/ $4.0 /)$.

\begin{abstract}
A series of xanthan gum/titanium dioxide-based polyurethane elastomers were synthesized through the prepolymer method by the step growth polymerization. In the present work, xanthan gum was used as a bioactive material, with $\mathrm{TiO}_{2}$ as a nanofiller. The structural characterization of newly prepared polyurethane samples was carried out with the help of Fourier Transform Infrared Spectroscopy. Thermogravimetric Analysis gave us the information about the thermal stability. Differential Scanning Calorimetry directs the thermal changes in the polyurethane samples. The Atomic Force Microscopy technique revealed that the degree of micro-phase separation increases by augmenting the $\%$ age of $\mathrm{TiO}_{2}$, which was further confirmed by X-Ray Diffraction results. XRD confirmed the crystallinity of the final sample at about $2 \theta=20^{\circ}$. Antimicrobial activity determined through the Disc Diffusion Method, and the results indicated that the synthesized polyurethane have antimicrobial activity. The water absorption capability of the polyurethane samples showed that these polymer samples are hydrophilic in nature.
\end{abstract}

Keywords: polyurethanes; xanthan gum; titanium dioxide; atomic force microscopy; X-Ray diffraction

\section{Introduction}

Polyurethanes have become the 6th most used group of polymers in the last few decades and have gained more importance due to multiple use in different fields, such as coatings, adhesives, furniture, and foams [1,2]. Polymeric composites are currently at an important crossroad, where research is shifted toward more sustainable bio-based materials. In the last few years, biomaterials and biocomposites have gained extraordinary attention. Biocomposites have additional benefits, apart from their eco-friendly nature [3]. Polyurethanes are often applied as biomaterials because they have good mechanical properties and low adsorption of biomolecules [4].

In recent years, numerous polymeric materials have utilized for the manufacturing of different medical devices that interact with blood, body liquids, and tissues [5]. The soft, as well as hard, segment of polyurethanes exhibited elastomeric properties [6]. Basically, the polyurethanes are incorporated in medical applications due to their toughness, cost effectiveness, and durability [7-9].

By comparing them with additives, they have gained much more attention due to ease of processing and, specifically, the countless architectural variety for optimizing their stages. The characteristics of the final polyurethane could be modified and controlled by 
the addition of additives [10]. They have a basic skeleton for lightweight materials, which is necessary for the transport industry. Reducing average weight decreases fuel usage, as well as greenhouse gases. Moreover, most of them are recyclable, bioactive, and biodegradable, depending upon the ingredients [11]. The physical properties of a polyurethane, such as density, tensile strength, high water abrasion, etc., distinguish its functioning [12]. They have admirable properties, such as hardness, tensile, compressive, impact resistance, etc. In general, polyurethanes are used in many different applications. These properties are tightly correlated with the biphasic nature of the segmented polyurethanes in the hard and soft phase. This, in turn, depends upon the chemical nature and composition of both phases. Flexible segment polyether and polyester-based polyurethanes (PUs) are susceptible to degradation under hydrolytic and oxidation environments [13].

The mechanical characterization of microcapsules of polyurethanes exhibits increased mechanical strength by a variable quantity of chain extenders, i.e., 1,4-butanediol (BDO) [14]. In the modern era, the standard of living could be enhanced with the employment of polymeric biomaterials. Generally, such biomaterials are simulated/artificial polymers, which are used in artificial organs, implants, dentistry, abrasion bandages, and drug delivery systems [15]. However, investigation on the degradation, morphology, and thermal and mechanical behavior is crucial to determine the end use of these materials.

In various extra and intracorporeal devices, biomedical polyurethanes are extensively applied. Typical illustrations include pacemaker leads insulation, indwelling tubes, heart pump tubes, and balloons of angioplasty [16]. Aliphatic diisocyanates, such as hexamethylene diisocyante (HDI), or cycloaliphatic diisocyanates, such as $4,4^{\prime}$ methylenebis(cyclohexyl isocyanate) $\left(\mathrm{H}_{12} \mathrm{MDI}\right)$ and isophorone diisocyanate (IPDI), have bid superior stability over the aromatic isocyanate. The aliphatic diisocyanates show improved phase separation compared to corresponding aromatic diisocyanates. They also show improved phase separation behavior over the corresponding aromatic diisocyanates [3]. Today, extensive studies have been accomplished on polyurethane due to their inimitable possessions, as well as to illustrate their different behaviors [17].

By supplementing the diols of lower molecular weight as chain extender, Barikani and Hepburn reported that thermal stability of polyurethanes was enhanced [18]. Polyurethane biocompatible organic polymers, with an alginate nucleus and chitosan shell, used as nanoparticles, were prepared for increasing encapsulation efficiency, more regular insulin liberation, and better insulin accessibility [19]. Today, polysaccharides extracted from plants, such as guar gum or pectin, and extracted from algae, such as alginate, are replaced by some bacterial exopolysaccharides, such as xanthan gum and gellan gum [20]. Xanthomonas campestris produces the xanthan gum, which is basically heteropolysaccharide. Xanthan gum has extensive applications in industries, such as food, oil, pharmaceuticals, etc., due to its rheological properties, i.e., pseudo plasticity, high viscosity, etc. [1].

Biopolymer collection has been turned into a noteworthy natural issue today because of expanding use of biomaterials for pharmaceutical applications. Reprocessing of polymeric wastes by recycling them has been extensively applied. Now, there is a dire need to synthesize environmentally friendly biodegradable polymer [15].

Biocompatibility is an index which is a basic requirement for a polymeric material to be appropriate as an ideal biomaterial, which, in turn, depends upon degradable nature, cytotoxicity, and the other mechanical properties [21].

A few biomaterials out of bulk commodity polymers have been found promising. The novel polymeric materials of nanocomposites of nylon 6/clay has led to emanation having unanimity of incomparable characteristics [22]. For structural development, the amalgamation of layered nanofillers can radically influence the blends' and polymers' microphase morphology by acting as templates [23]. In order to promote biodegradability and biocompatibility, current studies have marked the porosity worthy of acritical stuff, more distinctively, porosities distribution and structure [24].

In this study, the xanthan gum $/ \mathrm{TiO}_{2}$-based polyurethanes (XTPUs) were prepared by augmentation of weight (\% age) of $\mathrm{TiO}_{2}$, by the prepolymer method. The microstructure 
biocompatibility of the nanocomposites was investigated. It was hoped that the introduction of nano $\mathrm{TiO}_{2}$ could not only improve the physical properties and biocompatibility of $\mathrm{PU}$ but also inhibit the growth of bacteria even when nanofiller $\mathrm{TiO}_{2}$ were used in low concentrations and were embedded in the polyurethane (PU) matrix.

\section{Experimental}

\subsection{Materials and Synthesis}

Analytical grade chemicals were used in this research work, provided by Sigma Chemical Co. (St. Louis, MO, USA), including Hydroxyl-terminated polybutadiene (HTPB, $\mathrm{Mn}=3000 \mathrm{~g} / \mathrm{mol}$ ); Isophorone Diisocyanate (IPDI), 1,4-butanediol (BDO) was used as chain extender, titanium dioxide $\left(\mathrm{TiO}_{2}\right)$ was used as a nanofiller, and the commercial xanthan gum (XG) was used as bioactive material. These were used to synthesize polyurethanes' elastomers by the step growth synthesis method. Before the use of these chemicals, for removal of moisture, they were dried at $80^{\circ} \mathrm{C}$ in an electrical oven. During the drying process, they were placed in a vacuum for $24 \mathrm{~h}$.

The prepolymer synthesis was done, according to a reported method [25]. Firstly, $\mathrm{TiO}_{2}$ (\% by weight) and XG (\% by weight) were dispersed and mechanically stirred in one mole of HTPB for $2 \mathrm{~h}$ at $100{ }^{\circ} \mathrm{C}$ until it completely dispersed in four-necked speciallydesigned apparatus equipped with round bottom flask, heating oil bath, magnetic stirrer, reflux condenser, nitrogen inlet, and dropping funnel at $100{ }^{\circ} \mathrm{C}$. Then, it was reacted with two moles of IPDI for $2 \mathrm{~h}$ at $80-100{ }^{\circ} \mathrm{C}$, in order to obtain isocyanate terminated (NCO) polyurethane prepolymer. The stirring continued until NCO-terminated prepolymer was synthesized. Titration with n-butylamine (ASTM D 2572-80) was conducted to obtain the NCO contents of the polymer. The synthesis of prepolymer was confirmed using FT-IR spectroscopy [26].

\subsection{Synthesis of Final Polymer}

The final xanthan gum $/ \mathrm{TiO}_{2}$-based polyurethane (XTPU) polymer was obtained by stirring, for $30 \mathrm{~min}$, the polyurethanes prepolymer with the chain extender 1,4-butanediol $(1.2 \mathrm{~mol})$. On the appearance of homogeneity and completion of dispersion of the chain extender in the reaction mixture, the polymer, in liquid form, was poured on the Teflon plate in order to develop a sheet having thickness of almost $2-3 \mathrm{~mm}$. Then, at $100{ }^{\circ} \mathrm{C}$ for 24-48 $\mathrm{h}$, the circulating hot air oven was used to cure the synthesized polymer. Before testing, i.e., characterization by various techniques, the cured sheets was stored at $25^{\circ} \mathrm{C}$ for one week in order to attain almost $40 \%$ humidity. A series of six polymer samples were prepared by keeping constant the weight $\%$ age of $X G$, i.e., $1 \%$ and by varying weight $\%$ age of $\mathrm{TiO}_{2}$ from $0 \%$ to $5 \%$, as shown in Table 1 . Figure 1 presents the schematic demonstration of the chemical route for synthesis of the polymer.

Table 1. General formulation of polyurethanes.

\begin{tabular}{cccccc}
\hline $\begin{array}{c}\text { Sample } \\
\text { Code }\end{array}$ & $\begin{array}{c}\text { IPDI } \\
\text { (mole) }\end{array}$ & $\begin{array}{c}\text { HTPB } \\
\text { (mole) }\end{array}$ & $\begin{array}{c}\text { BDO } \\
\text { (mole) }\end{array}$ & $\begin{array}{c}\text { TiO }_{2} \\
\text { \% }\end{array}$ & $\begin{array}{c}\text { Xanthan } \\
\text { Gum \% }\end{array}$ \\
\hline XTPU-1 & 2 & 0.8 & 1.2 & 0 & 0 \\
XTPU-2 & 2 & 0.8 & 1.2 & 1 & 1 \\
XTPU-3 & 2 & 0.8 & 1.2 & 2 & 1 \\
XTPU-4 & 2 & 0.8 & 1.2 & 3 & 1 \\
XTPU-5 & 2 & 0.8 & 1.2 & 4 & 1 \\
XTPU-6 & 2 & 0.8 & 1.2 & 5 & 1 \\
\hline
\end{tabular}




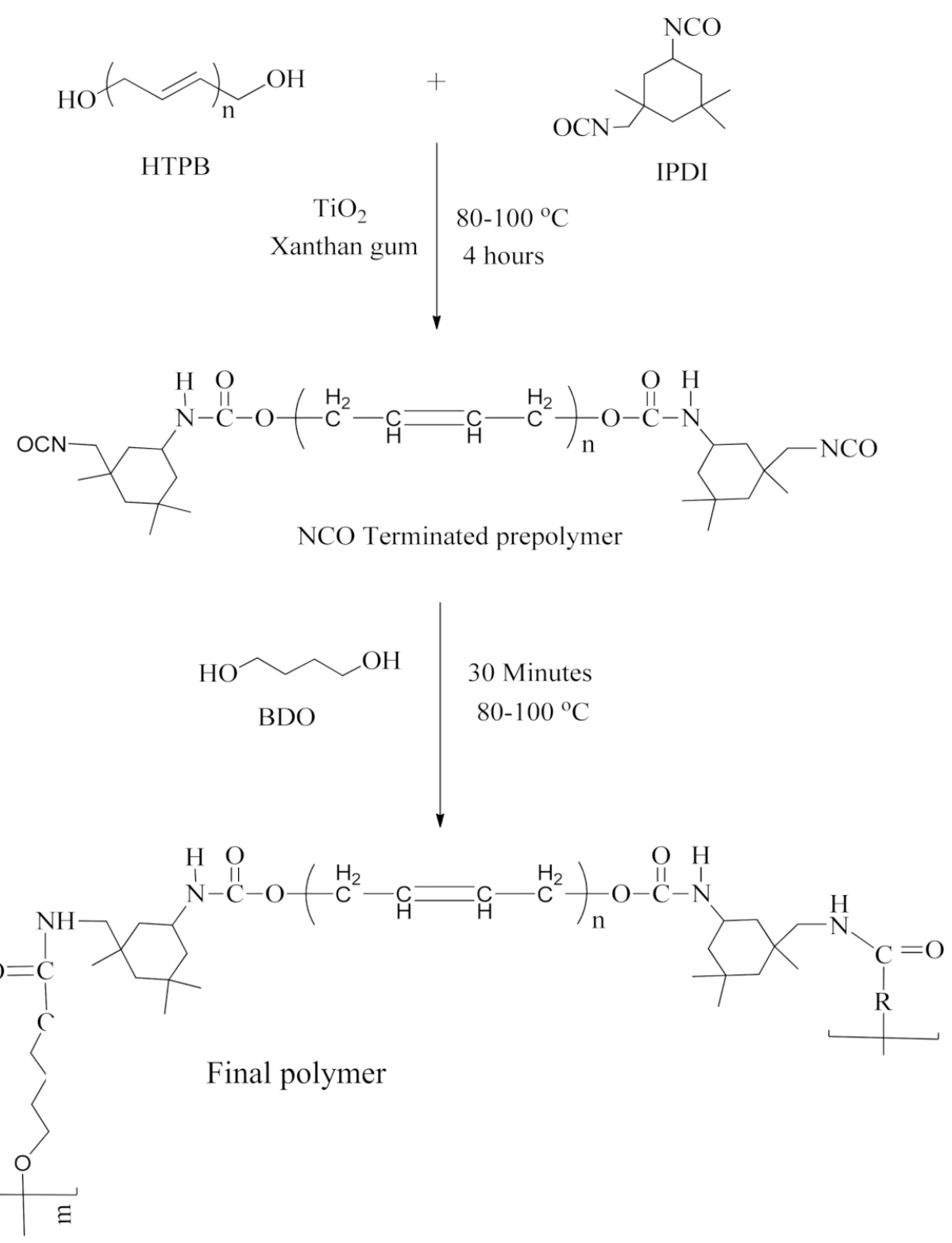

Figure 1. Synthesis of polyurethane.

\section{Characterization}

\subsection{Fourier Transform Infrared Spectroscopy (FT-IR)}

Structural characterization of synthesized polymer was done by BRUKER TENOSR II FT-IR spectrometer (Bruker, Billerica, MA, USA). The infrared spectra recorded after 15-s interludes, by using 8 scans over a resolutions of $2 \mathrm{~cm}^{-1}$. The $\mathrm{KBr}$ beam splitter and DTGS detector were provided to the spectrometer. Data was collected, processed, and presented by thermo scientific spectroscopy software against a time-dependent series. The mechanism of reaction, as well as crosslinking behavior, was interpreted by FT-IR [27].

\subsection{Atomic Force Microscopy (AFM)}

AFM (CP-II, Veeco, Newport Beach, CA, USA) was used to assess surface morphology of prepared samples. A phosphorus-doped silicon-integrated pyramidal tip was used as support, in order to acquire images in tapping mode with a triangular cantilever (force constant of 20-80 N/m). Simultaneously, the images of topography and phase separation were recorded. The root-mean square average of the surface roughness was calculated within the given area as the standard deviation of all heights. Image Pro Plus 4.5 software 
(Media Cybernetics, Rockville, MD, USA) was used to measure the average hard and soft domain size from the phase images [28].

\subsection{Thermogravimetric (TGA) and Differential Scanning Calorimeter (DSC)}

Thermogravimetric and Differential Scanning Calorimeter analysis were accomplished using an SDT Q600 V20.9 Build 20 (TA Instruments, Newcastle, DE, USA) under a dry nitrogen flow. The temperature range was set at $0-600{ }^{\circ} \mathrm{C}$, and tamp (heating) rate was retained at $10{ }^{\circ} \mathrm{C} / \mathrm{min}$. The samples for TGA and DSC were primed on a glass substrate by spin coating of the mixed solution. Then, it was cured at various temperature steps. Aluminium sample pans were utilized to seal the almost $4 \mathrm{mg}$ of each sample. Then, the prepared materials were analyzed under dry nitrogen by DSC over a heating rate of $10^{\circ} \mathrm{C} / \mathrm{min}$ from 0 to $500{ }^{\circ} \mathrm{C}$. The glass transition temperature (Tg) crystallization temperature (Tc) and melting temperature $(\mathrm{Tm})$ of the prepared polymers were investigated with the help of differential scanning calorimeter SDT Q600 V20.9 Build 20 [29].

\subsection{Antimicrobial Activity}

The capacity of a substance to have contact with the human body tissues without affecting the human body is called biocompatibility. The samples were subjected to assess the antimicrobial activity. The inhibition studies were done by actively growing bacterial cells. First of all, a nutrient agar media of $1000 \mathrm{~mL}$ was prepared, and $150 \mathrm{~mL}$ was poured in separate $150-\mathrm{mL}$ flasks. The autoclave was used for $15 \mathrm{~min}$ at $120^{\circ} \mathrm{C}$ by putting in agar medium nutrients flasks. Later on, it was cooled and bacteria, i.e., Escherichia coli (gram-negative) and Macrococcus (Gram-positive), were added to about $15 \mu \mathrm{L}$ in the above two flasks. The sterile petri plates were used, and almost $20 \mathrm{~mL}$ of each agar nutrient medium was transferred in these plates, while room temperature was maintained. For $24 \mathrm{~h}$, the samples were incubated at $37^{\circ} \mathrm{C}$, and they were then placed in petri dishes. The zone of inhibition, in which growth of bacteria was inhibited, was calculated by the diffusion active compound in the surrounding of the sample [30,31].

\subsection{X-Ray Diffractometry (XRD)}

In X-ray diffractometry, X-rays were used to irradiate XTPU polymers, and the scattering pattern was noted. Basically, the scattered radiations intensity noted as a function of the scattering angle $\theta$. The $\mathrm{X}$-rays scattering is due to electron density difference. A small angle scattering of $X$-Rays is used to investigate the microstructures in the range of tens to thousands angstrom $(\hat{\AA})$. It is basically a phase segregation in polymers. Meanwhile, X-ray scattering of a wide angle was also applied to calculate the crystallinity of the polymer samples at atomic level. The different reflections of XRD were the result of crystalline behavior of the polymer samples, which was calculated by using Bragg's law.

$$
2 d \sin \theta=n \lambda,
$$

where $d$ is the basically distance between crystalline planes, $\theta$ is the angle of X-ray beam which it makes with the planes, $n$ is an integer, and $\lambda$ is the wavelength. The dispersion

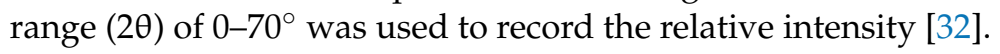

\section{Results and Discussion}

\subsection{FT-IR Analysis}

Figure 2 represents the FT-IR spectra of 1,4-butanediol, Isophrone Diisocyanate, HTPB, Xanthan Gum, NCO-terminated Prepolymer, and XTPU final Polymer. Figure 2a shows the FT-IR spectrum of 1, 4-butanediol and indicated that, due to the $\mathrm{OH}$ group, a very strong peak appeared at $3400 \mathrm{~cm}^{-1}$. Due to the $\mathrm{CH}_{2}$ group the peak appeared at $2900 \mathrm{~cm}^{-1}$. In Figure 2b, the FT-IR spectrum of IPDI showed the anti-symmetric stretching peak of the $\mathrm{CH}_{2}$ group at $2939.52 \mathrm{~cm}^{-1}$ and symmetric stretching peak of the $\mathrm{CH}_{2}$ group at $2862.0 \mathrm{~cm}^{-1}$ was also observed. In the spectrum of IPDI, due to the NCO group, a sharp peak at 
$2250.71 \mathrm{~cm}^{-1}$ was also observed. In Figure 2c, the FT-IR spectrum of HTPB where the peak of hydroxyl $(\mathrm{OH})$ appeared at $3736.12 \mathrm{~cm}^{-1}$ due to stretching vibration is shown. There appeared a peak due to anti-symmetric stretching vibration of the $\mathrm{CH}_{2}$ group, observed at $2945.30 \mathrm{~cm}^{-1}$. Figure $2 \mathrm{~d}$ shows the most significant bands for the xanthan gum in the range of 4000-500 $\mathrm{cm}^{-1}$. It includes an axial deformation of $\mathrm{OH}$ at $3300-3450 \mathrm{~cm}^{-1}$ and an axial deformation of C-H at $2855-2926 \mathrm{~cm}^{-1}$, which may due to absorption of symmetrical and asymmetrical stretching of $-\mathrm{CH}_{3}$ or may be due to $-\mathrm{CH}_{2}$-groups. There was also an aldehydic (-CHO) peak at $1710-1730 \mathrm{~cm}^{-1}$. An axial deformation of $\mathrm{C}-\mathrm{O}$ of enols was observed at $1530-1650 \mathrm{~cm}^{-1}$. An axial deformation of C-O at $1045-1150 \mathrm{~cm}^{-1}$ was also observed. In Figure 2e, the NCO-terminated prepolymer clearly showed that peaks due to the $\mathrm{OH}$ group diminished. The peak due to the $\mathrm{NH}$ group appeared at $3325 \mathrm{~cm}^{-1}$. The NCO group's intensity was lower to some extent, which means that isocyanate groups reacted completely. The formation of the prepolymer was confirmed by the appearance of peak of the NH group at $3325 \mathrm{~cm}^{-1}$ and supported its proposed structure. The antisymmetric peak of the $\mathrm{CH}_{2}$ group was seen at $2945.30 \mathrm{~cm}^{-1}$. The stretching peak of $-\mathrm{C}=\mathrm{O}$ was observed at $1724.36 \mathrm{~cm}^{-1}$. Figure $2 \mathrm{f}$ shows, by extending prepolymer with 1,4-BDO, that the FT-IR spectra showed a very strong peak at about $1707 \mathrm{~cm}^{-1}$, which was assigned to $\mathrm{C}=\mathrm{O}$ stretching of urethane. Peaks corresponding to the absorption of $\mathrm{NH}, \mathrm{C}=\mathrm{O}$, and $\mathrm{C}=\mathrm{O}$ were observed at $3325 \mathrm{~cm}^{-1}, 1707 \mathrm{~cm}^{-1}$ (non-hydrogen bonded), $1643 \mathrm{~cm}^{-1}$ (hydrogen bonded), and $1225 \mathrm{~cm}^{-1}$, respectively, which indicate the new synthesized product being in the urethane group. The observed N-H bending vibrations at $1598 \mathrm{~cm}^{-1}, \mathrm{C}-\mathrm{O}-\mathrm{C}$ stretching absorption band corresponding to linkage between $\mathrm{OH}$ and $\mathrm{NCO}$ groups to form urethane bond in the range 1057-1130 $\mathrm{cm}^{-1}$, also provide strong evidence for the formation of XTPU.

The FT-IR spectra of XTPU 1 to 6 with varying weight $\%$ age of $\mathrm{TiO}_{2}$ and constant weight $\%$ age, i.e., $1 \%$ xanthan gum, are shown in Figure 3. All the spectra confirm the formation of urethane linkage in the final XTPU polymer samples. In Figure 3, the XTPU-1 spectra showed the formation of urethane linkage NH at the peak $3750.17 \mathrm{~cm}^{-1}$, by the disappearing peak of $\mathrm{NCO}$ at $2156 \mathrm{~cm}^{-1}$. It showed the symmetric and asymmetric peak at $2840 \mathrm{~cm}^{-1}$ of the $-\mathrm{CH}_{2}$ group and $2913.45 \mathrm{~cm}^{-1}$, respectively. The peak of $-\mathrm{C}=\mathrm{O}$ group appeared at $1697.82 \mathrm{~cm}^{-1}$. FT-IR spectra of XTPU-2 is shown in Figure 3. This spectra showed the formation of urethane linkage $\mathrm{NH}$ at the peak $3750 \mathrm{~cm}^{-1}$. It also displayed the symmetric and a-symmetric peak of the $-\mathrm{CH}_{2}$ group at $2800 \mathrm{~cm}^{-1}$ and $2912.59 \mathrm{~cm}^{-1}$. The $-\mathrm{C}=\mathrm{O}$ group peak appeared at $1698.02 \mathrm{~cm}^{-1}$. The peak of NCO disappeared at $2160 \mathrm{~cm}^{-1}$. The FT-IR spectra of XTPU-3 is shown in Figure 3. This spectrum characterizes the peak of $-\mathrm{C}=\mathrm{O}$ group at $1698.02 \mathrm{~cm}^{-1}$. The peak of $\mathrm{N}-\mathrm{H}$ forms at $3750.13 \mathrm{~cm}^{-1}$. It also gives the symmetric and a-symmetric peak at $2850 \mathrm{~cm}^{-1}$ and $2911.38 \mathrm{~cm}^{-1}$. Figure 3 shows the FT-IR spectra of XTPU-4. This spectrum characterizes the peak of $-\mathrm{C}=\mathrm{O}$ group at $1698.02 \mathrm{~cm}^{-1}$. The peak of N-H forms at $3853.72 \mathrm{~cm}^{-1}$. It also gives the symmetric and a-symmetric peak at $2843.05 \mathrm{~cm}^{-1}$ and $2913.05 \mathrm{~cm}^{-1}$. In Figure 3, the FT-IR spectra of XTPU-5 shows the formation of $\mathrm{N}-\mathrm{H}$ at $3760 \mathrm{~cm}^{-1}$. It shows the formation of $-\mathrm{C}=\mathrm{O}$ peak at $1698.05 \mathrm{~cm}^{-1}$. It also shows the a-symmetric and symmetric peaks of $\mathrm{CH}_{2}$ group at $2950 \mathrm{~cm}^{-1}$ and 2840 $\mathrm{cm}^{-1}$. Furthermore, it gives information about the disappearing peak of the NCO group at $2300 \mathrm{~cm}^{-1}$. Figure 3 also shows FT-IR spectra of XTPU- 6 and confirmed the formation of $\mathrm{N}-\mathrm{H}$ at $3753 \mathrm{~cm}^{-1}$. Moreover, it illustrates the formation of $-\mathrm{C}=\mathrm{O}$ peak at 1697.97 $\mathrm{cm}^{-1}$. It shows the a-symmetric and symmetric peaks of $-\mathrm{CH}_{2}-$ group at $2912.56 \mathrm{~cm}^{-1}$ and $2843 \mathrm{~cm}^{-1}$. It also gives information about the disappearing peak of the NCO group at $2300 \mathrm{~cm}^{-1}$.

\subsection{Evaluation of Antimicrobial Activity}

The gram positive, as well as gram negative, bacteria and fungi were used for antimicrobial activity, so they can be classified as evaluation of antibacterial activity and evaluation of antifungal activity. 


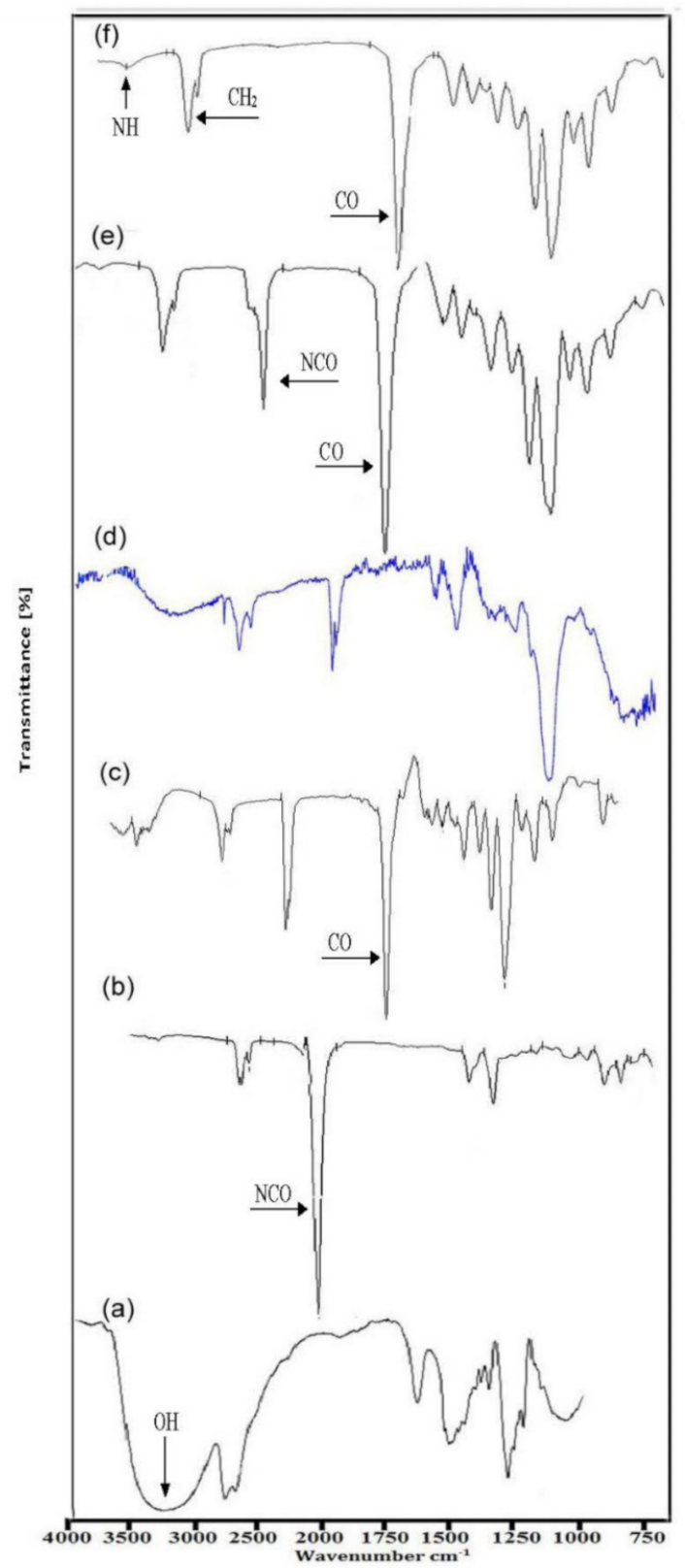

Figure 2. FT-IR spectra of (a) 1,4-Butanediol (BDO), (b) Isophrone diisocyanate, (c) Hydroxyl Terminated Polybutadiene (HTPB), (d) Xanthan Gum (XG), (e) NCO-terminated Prepolymer, and (f) XTPU final Polymer.

\subsubsection{Evaluation of Antibacterial Activity}

Biocompatibility is necessary for any material to be in contact with living tissues without resulting any harm to living body. Most polyurethane polymers are biocompatible, and their biocompatibility was evaluated by antibacterial activity. Antibacterial analysis was carried out through the disc diffusion technique, and Escherichia coli and Macrococcus (a gram negative and gram positive, respectively) strains of bacteria were used for this purpose. On agar plates, the bacterial cultures were spread, and punched samples of polyurethane polymer of $5 \mathrm{~mm}$ diameter samples were applied over the plates. This complete setup was carried out at $37^{\circ} \mathrm{C}$ in an incubator overnight. The results for biocompatibility with E. coli and Macrococcus are presented in Figure 4. The resistance of polyurethane samples against $E$. coli the gram negative and Macrococcus the gram positive bacteria are shown in the inhibition zone. It was found that antibacterial ability or biodegradability of a polymer depends upon the concentration of $\mathrm{TiO}_{2}$, along with content of xanthan gum used. We may 
increase the quality by changing the composition. It was observed that samples based on $\mathrm{BDO}$ show less antibacterial activity against $E$. coli. Antibacterial activity was influenced by bacterial strain used as given in results as reported in literature [30].

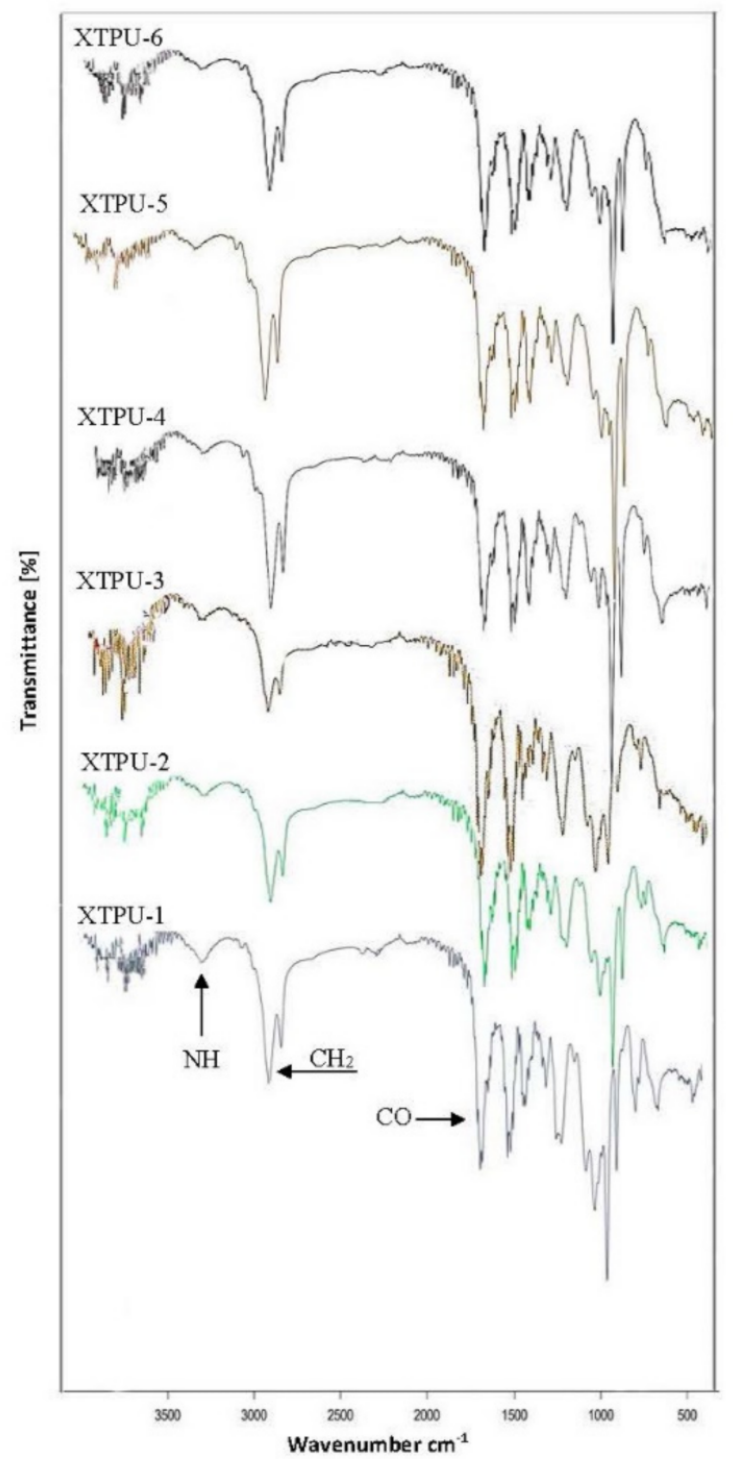

Figure 3. FT-IR spectrum of polyurethane samples XTPUs having $0-5 \% \mathrm{TiO}_{2}$, respectively.

\subsubsection{Evaluation of Antifungal Activity}

Antifungal activity was evaluated against Aspergillus flavus using disc diffusion method. Vogel's media was used for fungal culture growth. The selected polyurethane polymer samples were punched in disc of $5 \mathrm{~mm}$ diameter and applied over the place incubated at $37^{\circ} \mathrm{C}$ overnight in incubator. Antifungal activity of 6 polyurethane samples with a variable content of Titanium dioxide and $1 \%$ xanthan gum was evaluated. The observed antifungal activity is shown in Figure 5. A clear zone of inhibition was observed on the plates of XTPU-5 and XTP-6; however, other polymer samples inhibited fungal growth at the area under the sample disc. The results exhibited that antifungal or biodegradability of polymer depends upon the content of $\mathrm{TiO}_{2}$ used. We may increase the quality by changing the composition. Moreover, the zone of inhibition can be increased by increasing the weight $\%$ age of $\mathrm{TiO}_{2}$. 


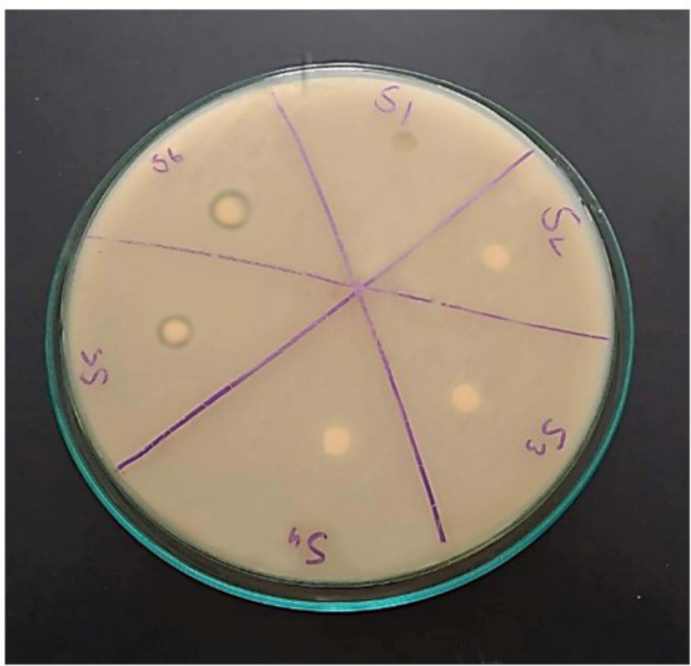

(a) E. coli (gram negative)

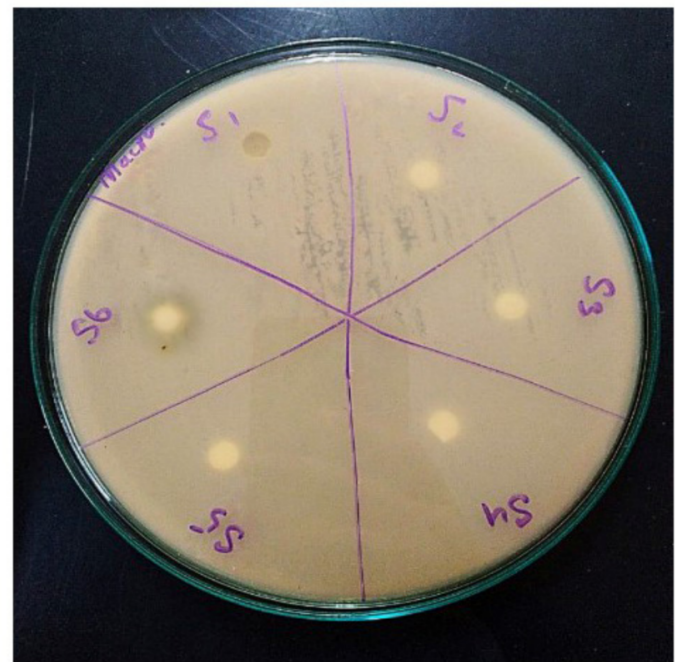

(b) Macrococcus (gram positive)

Figure 4. Antibacterial assay of samples against E. coli and Macrococcus.

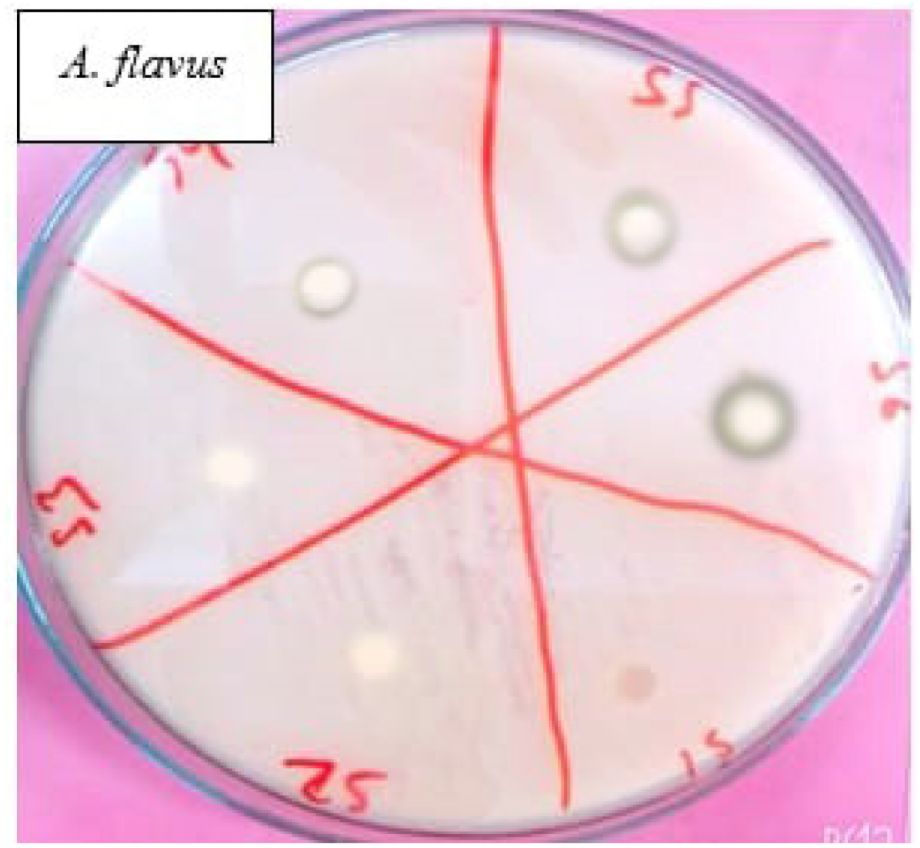

Figure 5. Antifungal assay of polyurethane samples against Aspergillus flavus.

\subsection{Thermal Analysis}

The thermal analyses of xanthan gum, titanium dioxide-based polyurethanes were performed by Thermogravimetric analysis (TGA) and Differential Scanning Calorimetry (DSC). These analyses are further explained below.

\subsubsection{Thermogravimetric Analysis (TGA)}

The thermal properties of xanthan gum, titanium dioxide-based polyurethanes (XTPU) were analyzed by using the TGA technique. The TGA thermograms of XTPU 1 to 6 are shown in Figure 6. The thermograms of TGA of all XTPU samples showed thermal stability and thermal degradation behavior. In an inert atmosphere, the thermal analysis data revealed that all of the XTPU polymer samples are thermally stable up to $140-225{ }^{\circ} \mathrm{C}$. All the polymer samples faced a $10 \%$ loss of weight in the range of $305-355^{\circ} \mathrm{C}$. These 
samples faced a $20 \%$ loss of weight in the range of $372-410{ }^{\circ} \mathrm{C}$. They also faced a $50 \%$ loss of weight in the range of $423-463^{\circ} \mathrm{C}$, and maximum decomposition observed in the samples occurred at $460-495^{\circ} \mathrm{C}$. The comparative results showed that the chain extender, i.e., BDO, and bioactive material, i.e., xanthan gum, play a vital role. The results illustrated that poly (ethylene glycol adipate)-based polyurethane [33] is thermally less stable compared to xanthan gum, $\mathrm{TiO}_{2}$-based polyurethanes with $\mathrm{BDO}$ as a chain extender. The values of temperature showed that pure polymers have lower degradation temperature, i.e., $460{ }^{\circ} \mathrm{C}$, while, at the same time, the polymers having $1 \% \mathrm{XG}, 5 \%$ of $\mathrm{TiO}_{2}$ have higher degradation temperature, i.e., $495^{\circ} \mathrm{C}$, showing degradation temperature variation about $35^{\circ} \mathrm{C}$. Results revealed that the percentage mole ratio of xanthan gum and $\mathrm{TiO}_{2}$ enhances the degradation temperature of polyurethane more than pure polyurethane, i.e., XTPU-1. The chain extender, i.e., $\mathrm{BDO}$, and xanthan gum increase the decomposition temperature and thermal stability of XTPU, as shown in Table 2.

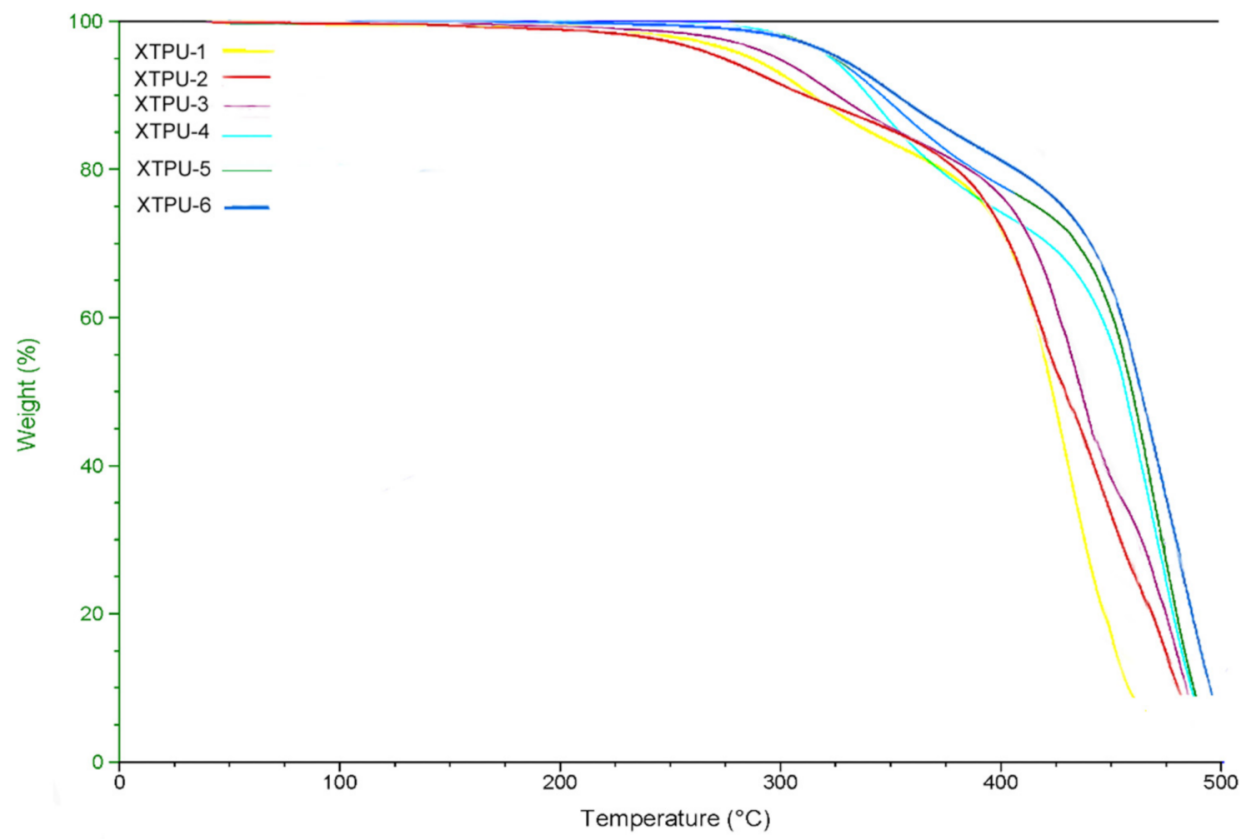

Figure 6. TGA thermogram of XTPUs at $500^{\circ} \mathrm{C}$.

Table 2. Thermal stability data of the XTPU samples based on TGA.

\begin{tabular}{|c|c|c|c|c|c|c|c|c|c|c|}
\hline $\begin{array}{l}\text { Sample } \\
\text { Code }\end{array}$ & $\begin{array}{l}\text { IPDI } \\
\text { (mole) }\end{array}$ & $\begin{array}{l}\text { HTPB } \\
\text { (mole) }\end{array}$ & $\begin{array}{l}\text { BDO } \\
\text { (mole) }\end{array}$ & $\begin{array}{c}\mathrm{TiO}_{2} \\
\%\end{array}$ & $\begin{array}{c}\text { X.G } \\
\%\end{array}$ & $\begin{array}{c}\mathrm{T}_{0} \\
\left({ }^{\circ} \mathrm{C}\right)\end{array}$ & $\begin{array}{l}\mathrm{T}_{20} \\
\left({ }^{\circ} \mathrm{C}\right)\end{array}$ & $\begin{array}{l}\mathrm{T}_{50} \\
\left({ }^{\circ} \mathrm{C}\right)\end{array}$ & $\begin{array}{l}\mathrm{T}_{80} \\
\left({ }^{\circ} \mathrm{C}\right)\end{array}$ & $\begin{array}{l}T_{\max } \\
\left({ }^{\circ} \mathrm{C}\right)\end{array}$ \\
\hline $\begin{array}{c}\text { XTPU- } \\
1\end{array}$ & 2 & 0.8 & 1.2 & 0 & 0 & 140 & 372 & 423 & 448 & 460 \\
\hline $\begin{array}{c}\text { XTPU- } \\
2\end{array}$ & 2 & 0.8 & 1.2 & 1 & 1 & 150 & 380 & 430 & 470 & 479 \\
\hline $\begin{array}{c}\text { XTPU- } \\
3\end{array}$ & 2 & 0.8 & 1.2 & 2 & 1 & 162 & 385 & 435 & 475 & 485 \\
\hline $\begin{array}{c}\text { XTPU- } \\
4\end{array}$ & 2 & 0.8 & 1.2 & 3 & 1 & 190 & 372 & 455 & 479 & 487 \\
\hline $\begin{array}{c}\text { XTPU- } \\
5\end{array}$ & 2 & 0.8 & 1.2 & 4 & 1 & 210 & 390 & 457 & 482 & 489 \\
\hline $\begin{array}{l}\text { XTPU- } \\
6\end{array}$ & 2 & 0.8 & 1.2 & 5 & 1 & 225 & 405 & 467 & 485 & 495 \\
\hline
\end{tabular}

Temperature at which $0 \%, 20 \%, 50 \%$, and $80 \%$ weight losses obtained from TGA. Maximum decomposition temperature obtained from TGA. 


\subsubsection{Differential Scanning Calorimetry (DSC) Study}

The effect of chain extenders length, $\mathrm{XG}$, and $\mathrm{TiO}_{2}$-based polyurethanes samples were also studied by DSC measurements. The XTPU thermograms are shown in Figure 7. In the XTPU 1 to 6 samples, it is clear by DSC analysis that thermal changes took place when temperature was increased from 0 to $500{ }^{\circ} \mathrm{C}$. It is clear from the data of Table 3 and from DSC thermograms that polymer degradation started in the range of $140-225^{\circ} \mathrm{C}$, which is also in accordance with TGA thermograms. The polymers samples showed glass transition temperature $(\mathrm{Tg})$ in between $178-193{ }^{\circ} \mathrm{C}$, crystallization temperature in the range $368-373{ }^{\circ} \mathrm{C}$, melting temperature $(\mathrm{Tm})$ in the range of $430-450{ }^{\circ} \mathrm{C}$, and decomposition/degradation temperature in the range of $460-495^{\circ} \mathrm{C}$ [34]. Here, it has been observed that the melting transition was found to be high near the decomposition temperature. This causes an arrangment of the chains and facilitates a greater interaction between chains, increasing the miscibility between the rigid and soft segment, as seen in TM and Tc, for all materials. The glass transition temperature observed at these values is relative to the rigid segment. The value of the $\mathrm{Tg}$ of the polyurethane sometimes also depends on the type of nanofiller $\left(\mathrm{TiO}_{2}\right)$ employed in the synthesis. This value is indicative of the soft and rigid segment mixing degee. The higher value of $\mathrm{Tg}$ usually represents the higher miscibilty or campatibity degree of rigid-flexible segments [35]. The results revealed that presence of a nanofiller, i.e., $\mathrm{TiO}_{2}$, and its bonding between xanthan gum and diisocyanate, i.e., IPDI, increases the stability and crystalline behavior of the synthesized polymer. So, the crystillinity may be observed because of nanofiller. The most probable reason for this behavior in the nanocomposite is reduction in mobility of chains of urethanes, which reduces the process of degradation, as reported in literature [36]. This can also be related to the formation of longer crosslinked microdomains of rigid segments or the structure with a greater degree of organization. This trend agrees with the results obtained in the literature.

Table 3. Thermal stability data of the XTPU samples based on DSC.

\begin{tabular}{|c|c|c|c|c|c|c|c|c|c|}
\hline $\begin{array}{l}\text { Sample } \\
\text { Code }\end{array}$ & $\begin{array}{c}\text { IPDI } \\
\text { (mole) }\end{array}$ & $\begin{array}{l}\text { HTPB } \\
\text { (mole) }\end{array}$ & $\begin{array}{c}\text { BDO } \\
\text { (mole) }\end{array}$ & $\begin{array}{c}\mathrm{TiO}_{2} \\
\%\end{array}$ & X.G \% & $\begin{array}{c}\mathrm{T}_{\mathrm{g}} \\
\left({ }^{\circ} \mathrm{C}\right)\end{array}$ & $\begin{array}{c}\mathrm{T}_{\mathrm{c}} \\
\left({ }^{\circ} \mathrm{C}\right)\end{array}$ & $\begin{array}{l}\mathrm{T}_{\mathrm{m}} \\
\left({ }^{\circ} \mathrm{C}\right)\end{array}$ & $\begin{array}{c}\mathrm{T}_{\mathrm{d}} \\
\left({ }^{\circ} \mathrm{C}\right)\end{array}$ \\
\hline $\begin{array}{c}\text { XTPU- } \\
1\end{array}$ & 2 & 0.8 & 1.2 & 0 & 0 & 178 & 368 & 430 & 460 \\
\hline $\begin{array}{c}\text { XTPU- } \\
2\end{array}$ & 2 & 0.8 & 1.2 & 1 & 1 & 180 & 365 & 435 & 479 \\
\hline $\begin{array}{c}\text { XTPU- } \\
3\end{array}$ & 2 & 0.8 & 1.2 & 2 & 1 & 183 & 370 & 435 & 485 \\
\hline $\begin{array}{c}\text { XTPU- } \\
4\end{array}$ & 2 & 0.8 & 1.2 & 3 & 1 & 185 & 370 & 440 & 487 \\
\hline $\begin{array}{c}\text { XTPU- } \\
5\end{array}$ & 2 & 0.8 & 1.2 & 4 & 1 & 191 & 371 & 447 & 489 \\
\hline $\begin{array}{c}\text { XTPU- } \\
6\end{array}$ & 2 & 0.8 & 1.2 & 5 & 1 & 193 & 373 & 450 & 495 \\
\hline
\end{tabular}

$T_{g}$ is Glass transition temperature; $T_{c}$ is Crystallization temperature; $T_{m}$ is melting temperature; $T_{d}$ is degradation/decomposition temperature.

\subsection{X-ray Diffraction Study}

The crystalline behavior of XTPU samples was calculated by using the crystalline peak intensity of respective samples. The Debye-Scherer (powder) method, applying Bragg's relation, was used to estimate the d-spacing of various XTPUs [37].

In XTPU samples, relative contents, structure regularity, and thermodynamic incompatibility affect the phase separation of soft, as well as hard, segment. A well oriented crystallinity was perceived at $2 \theta=20^{\circ}$, as reported in literature [38]. The phase separation of the soft and hard segment in XTPUs is attributed to crystallinity of sample, and it was revealed by X-ray diffraction studies. So, crystalline behavior improved as $\%$ age of $\mathrm{TiO}_{2}$ in the final XTPU increased. Finally, in the current study, we can attribute the crystallinity to the soft segment, and increasing percentage of $\mathrm{TiO}_{2}$ did not show any appreciable change 
in polymer structure. The chemical cross-linking of xanthan gum restricts the soft segment melting. So, it can be determined that only XTPU-6, having $1 \%$ xanthan gum and $5 \% \mathrm{TiO}_{2}$, showed higher crystallinity, which has been associated with phase separation at $2 \theta=20^{\circ}$, as shown in Figure 8.

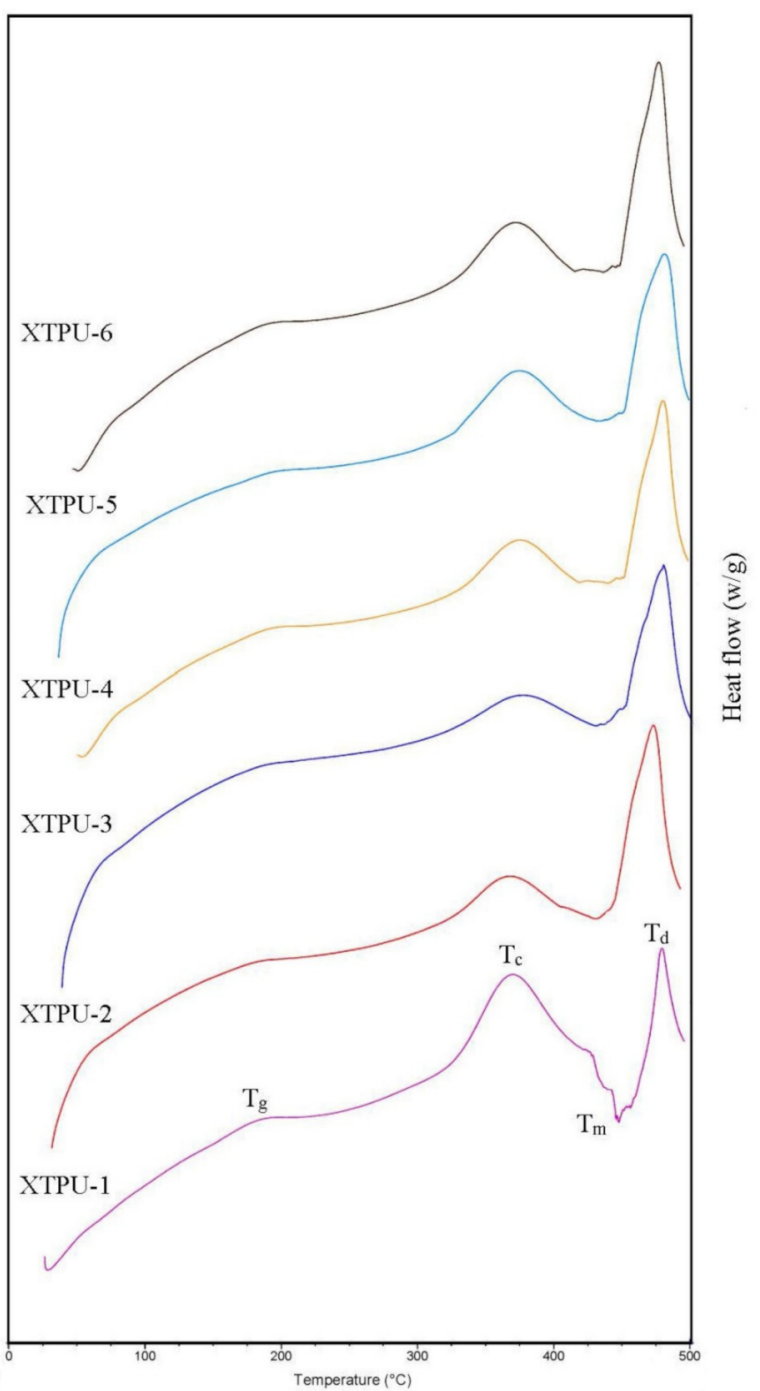

Figure 7. DSC curves of XTPU-1, 2, 3, 4, 5, and 6 at $500{ }^{\circ} \mathrm{C}$.

\subsection{Atomic Force Microscopy (AFM)}

The change in surface morphology of XTPU samples was mainly investigated by AFM. It provides important information relating surface characterization. In the current study, the final morphology of XTPUs films is visualized in Figure 9. In these phase images, the darker regions correspond to soft segments, while lighter domain or crystalline regions correspond to hard segments [2]. The XTPUs can be visualized for the microphase structures as a roughness gradient of $2.5 \mu \mathrm{m}, 158 \mathrm{~nm}$, and $300 \mathrm{~nm}$ for XTPU-1, XTPU-3, and XTPU-6 respectively. The complete and better dispersion of nanofiller, also with biomaterial, was also observed within samples. These results showed (the circled region) homogeneous structure of polymer and pattern of distribution of xanthan gum with $\mathrm{TiO}_{2}$ in the polyurethane polymer. AFM images of XTPUs have shown that hard segments are completely dispersed in the soft segment matrix. Moreover, it was inferred that, by increasing the content of $\mathrm{TiO}_{2}$ from $0 \%$ to $5 \%$ in 6 polymer samples from XTPU- 1 to XTPU-6, the order in pattern crystalline character and stability increases and cracking decreases in the polymer, according to reported literature [25]. Morover, in regard to 
polyurethane composition, it was also reported that hydrogen bonding was present in urethane groups, which may be the cause of phase segregation. The higher molecular weight of macrodiol and xanthan gum provided ordered and compact arrangments of soft and hard phases. However, various factors can be reponsible for phase segregation in PU, such as the diminsions of soft and hard segments, the polarity of groups, the chemical nature, and molecular weight $[37,39]$.
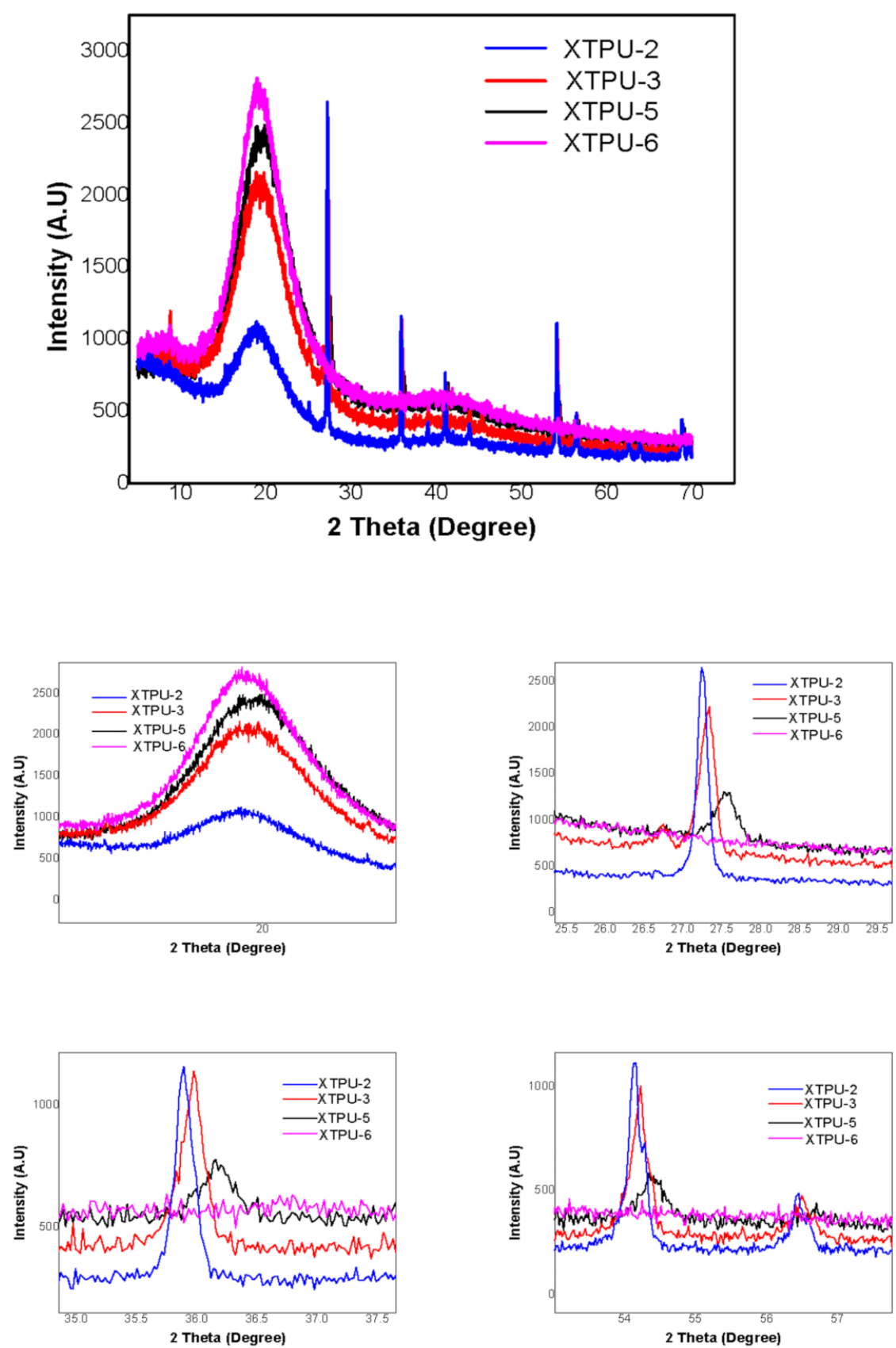

Figure 8. X-ray diffractograms of XTPU-2, XTPU-3, XTPU-5, and XTPU-6 with varying titanium dioxide $\%$ age. 
XTPU-1
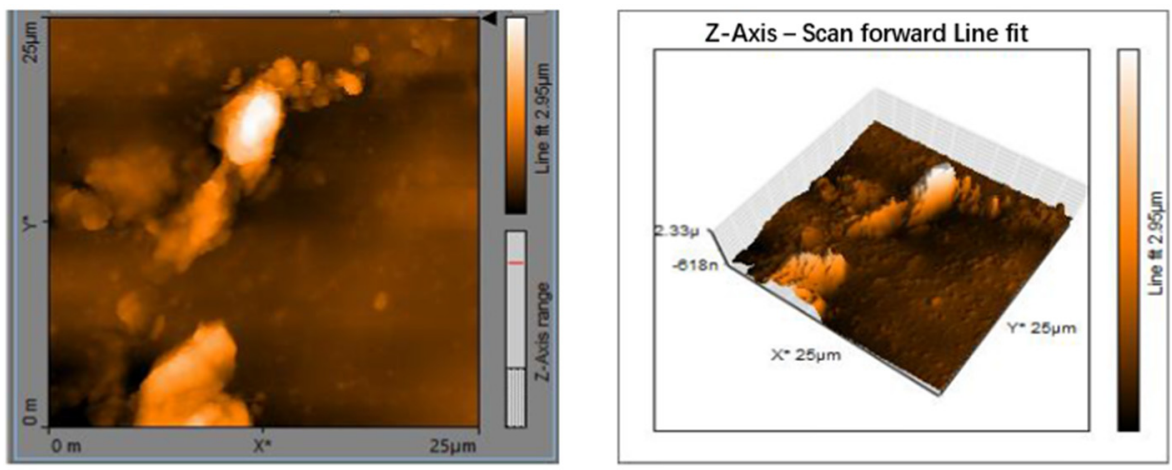

XTPU -3
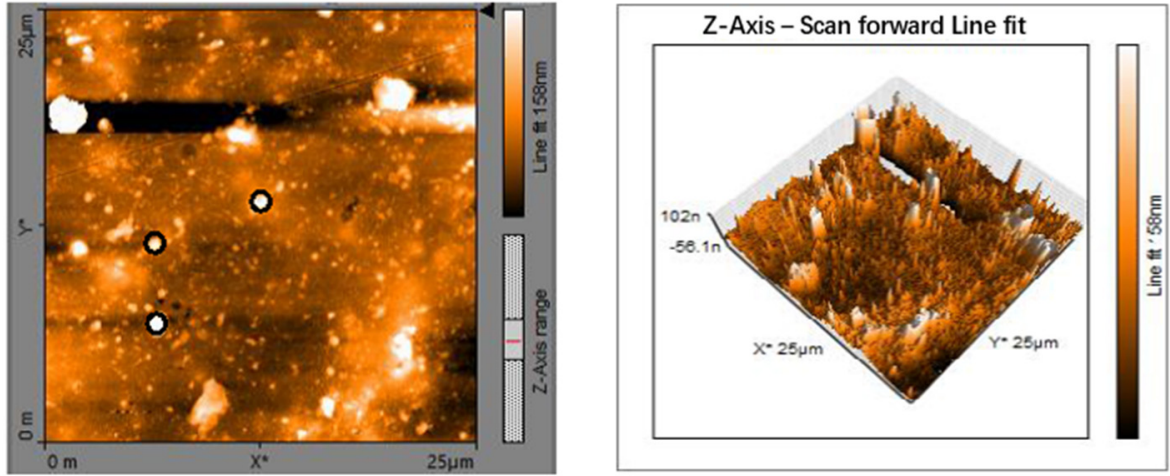

\section{XTPU -6}
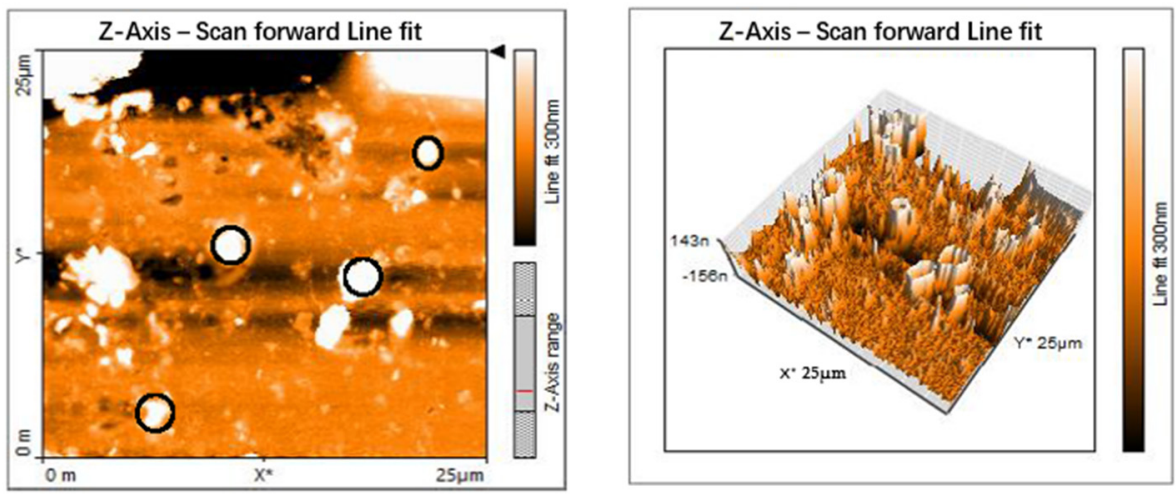

Figure 9. Three-dimensional AFM images of XTPU-1, XTPU-3, and XTPU-6 with 0\%, 2\%, and 5\% titanium dioxide, respectively.

\subsection{Evaluation of Water Absorption}

The water absorption test and hydrophobicity/hydrophilicity of polyurethane samples are used for evaluation of biodegradability of synthesized polymer. The degree of swelling of polymer components and their affinity to water is one of the indices of decomposition rate of polymeric materials under the influence of environmental factors. Due to presence of soft segment HTPB and XG into the back bone, the prepared polymers are hydrolytic resistant and can be utilized to perform indoor and outdoor environments. So, water absorption capability can be used to determine the hydrolytic degradation of them. The investigation of the hydrolytic stability of XTPUs has shown an increase of the water absorption. Such an increase may be due to the presence of free polar fragments (OH groups), which determine the hydrophilic properties of the polymer. Probably, a part of XG hydrophilic hydroxyls involved in the formation of intermolecular bonds with the polar groups of XTPUs remains unengaged [40]. Water absorption as a function of time 
and type of samples is summarized in Table 4 . Water absorption was calculated by the following formula:

$$
\text { Water absorption }(\%)=\frac{\mathrm{m}_{\mathrm{w}}-\mathrm{m}_{\mathrm{d}}}{\mathrm{m}_{\mathrm{d}}} \times 100
$$

where $m_{d}$ and $m_{w}$ are the masses of dry and wet XTPU samples, accordingly [38]. There was a remarkable water absorption indicated with passage of time in these prepared samples of polyurethanes. The results noticeably indicated that the polymer samples are hydrophilic in nature [41].

Table 4. Percentage of water absorption.

\begin{tabular}{cccccccc}
\hline \multirow{2}{*}{ Sr. No } & Samples & Temperature & \multicolumn{5}{c}{ \% Age of Water Absorption } \\
& Code & $\left({ }^{\circ} \mathbf{C}\right)$ & Day 1 & Day 2 & Day 3 & Day 4 & Day 5 \\
\hline 01 & XTPU-1 & 37 & 0.94 & 0.95 & 0.98 & 1.10 & 1.21 \\
02 & XTPU-2 & 37 & 0.95 & 0.96 & 0.99 & 1.10 & 1.23 \\
03 & XTPU-3 & 37 & 0.95 & 0.98 & 1.10 & 1.21 & 1.31 \\
04 & XTPU-4 & 37 & 1.10 & 1.20 & 1.3 & 1.5 & 1.61 \\
05 & XTPU-5 & 37 & 1.80 & 1.85 & 1.90 & 1.95 & 1.99 \\
06 & XTPU-6 & 37 & 1.96 & 1.98 & 1.99 & 2.0 & 2.1 \\
\hline
\end{tabular}

\section{Conclusions}

Xanthan gum/Titanium dioxide-based polyurethane elastomers with concordant crystallinity and hydrophilicity were synthezied. The reactants were HTPB, IPDI, and Titanium dioxide that produced prepolymer, extended with BDO. Xanthan gum was used as a bioactive material. Molecular characterization of the prepared elastomers was carried out by FT-IR spectroscopy, and the appearance of NH peaks with disappearance of NCO and $\mathrm{OH}$ peaks indicates that the proposed structure of polyurethane has been accomplished. The AFM technique revealed that the degree of micro-phase separation increases with augmenting \% age of $\mathrm{TiO}_{2}$, which was further confirmed by $\mathrm{XRD}$ results. It was revealed by XRD that the crystalline behavior of the synthesized samples due to amorphous region of macrodiol. The \% age of $\mathrm{TiO}_{2}$ influence on TGA and DSC values gave the information about the thermal stability and thermal changes in the polyurethane samples. The higher value of DSC is due to segments' mobility in the hard blocks' microregions (hard domain) and their destruction. Such changes may be caused by three-dimensional XG molecules, which form steric hindrence during polymer formation. Antimicrobial activity determined through the Disc Diffusion Method and the results indicated that the synthesized polyurethane had antimicrobial activity against the Macrococcus, E. coli, and Aspergillus flavus.

Author Contributions: Conceptualization, S.N. and S.H.; methodology, S.N. and M.S.; formal analysis, S.N. and N.R.; investigation, M.S. and S.N.; data curation, M.S., S.N. and N.R.; writingoriginal draft preparation, M.S.; writing—-review and editing, M.S., S.N., Z.S. and R.Z.; supervision, S.N.; project administration, S.N., N.R. and S.K. All authors have read and agreed to the published version of the manuscript.

Funding: The authors sincerely appreciate funding from Researchers Supporting Project number (RSP-2021/399), King Saud University, Riyadh, Saudi Arabia.

Institutional Review Board Statement: Not applicable.

Informed Consent Statement: Not applicable.

Data Availability Statement: The data presented in this study are available on request from the corresponding author.

Conflicts of Interest: The authors declare no conflict of interest. 


\section{References}

1. Zhang, Z.-G.; Chen, H.-Z. Xanthan production on polyurethane foam and its enhancement by air pressure pulsation. Appl. Biochem. Biotech. 2010, 162, 2244-2258. [CrossRef]

2. Klinedinst, D.B.; Yilgör, E.; Yilgör, I.; Beyer, F.L.; Wilkes, G.L. Structure-property behavior of segmented polyurethaneurea copolymers based on an ethylene-butylene soft segment. Polymer 2005, 46, 10191-10201. [CrossRef]

3. Hottle, T.A.; Bilec, M.M.; Landis, A.E. Sustainability assessments of bio-based polymers. Polym. Degrad. Stab. 2013, 98, 1898-1907. [CrossRef]

4. Huang, S.L.; Chao, M.S.; Ruaan, R.C.; Lai, J.Y. Microphase separated structure and protein adsorption of polyurethanes with butadiene soft segment. Eur. Polym. J. 2000, 36, 285-294. [CrossRef]

5. Ishihara, K.; Iwasaki, Y. Biocompatible elastomers composed of segmented polyurethane and 2-methacryloyloxyethyl phosphorylcholine polymer. Polym. Adv. Technol. 2000, 11, 626-634. [CrossRef]

6. Zia, K.M.; Zuber, M.; Bhatti, I.A.; Barikani, M.; Sheikh, M.A. Evaluation of biocompatibility and mechanical behavior of polyurethane elastomers based on chitin/1, 4-butane diol blends. Int. J. Biol. Macromol. 2009, 44, 18-22. [CrossRef] [PubMed]

7. Middleton, J.C.; Tipton, A.J. Synthetic biodegradable polymers as orthopedic devices. Biomaterials 2000, 21, 2335-2346. [CrossRef]

8. Wang, Y.; Hong, Q.; Chen, Y.; Lian, X.; Xiong, Y. Surface properties of polyurethanes modified by bioactive polysaccharide-based polyelectrolyte multilayers. Colloids Surfaces B Biointerfaces 2012, 100, 77-83. [CrossRef] [PubMed]

9. Zhou, B.; Hu, Y.; Li, J.; Li, B. Chitosan/phosvitin antibacterial films fabricated via layer-by-layer deposition. Int. J. Boil. Macromol. 2014, 64, 402-408. [CrossRef]

10. Szycher, M. Szycher's Handbook of Polyurethanes, 2nd ed.; CRC Press: Boca Raton, FL, USA, 2012.

11. Gaidukova, G.; Ivdre, A.; Fridrihsone, A.; Verovkins, A.; Cabulis, U.; Gaidukovs, S. Polyurethane rigid foams obtained from polyols containing bio-based and recycled components and functional additives. Ind. Crop. Prod. 2017, 102, 133-143. [CrossRef]

12. Kuan, H.; Ma, C.-C.M.; Chang, W.-P.; Yuen, S.-M.; Wu, H.-H.; Lee, T.-M. Synthesis, thermal, mechanical and rheological properties of multiwall carbon nanotube/waterborne polyurethane nanocomposite. Compos. Sci. Technol. 2005, 65, 1703-1710. [CrossRef]

13. Zia, K.M.; Bhatti, H.N.; Bhatti, I.A. Methods for polyurethane and polyurethane composites, recycling and recovery: A review. React. Funct. Polym. 2007, 67, 675-692. [CrossRef]

14. Hu, Y.; Liu, C.; Shang, Q.; Zhou, Y. Synthesis and characterization of novel renewable castor oil-based UV-curable polyfunctional polyurethane acrylate. J. Coatings Technol. Res. 2017, 15, 77-85. [CrossRef]

15. Nair, L.S.; Laurencin, C.T. Biodegradable polymers as biomaterials. Prog. Polym. Sci. 2007, 32, 762-798. [CrossRef]

16. Gorna, K.; Gogolewski, S. Molecular stability, mechanical properties, surface characteristics and sterility of biodegradable polyurethanes treated with low-temperature plasma. Polym. Degrad. Stab. 2003, 79, 475-485. [CrossRef]

17. Barikani, M.; Hepburn, C. The relative thermal stability of polyurethane elastomers. II: Influence of polyol-diisocyanate molar block ratios with a single and mixed diisocyanate system. Cell. Polym. 1987, 6, 29-36.

18. Tant, M.R.; McManus, H.L.N.; Rogers, M.E. High-Temperature Properties and Applications of Polymeric Materials; ACS Publications: Washington, DC, USA, 1995; pp. 1-20. [CrossRef]

19. Bhattacharyya, A.; Mukherjee, D.; Mishra, R.; Kundu, P. Preparation of polyurethane-alginate/chitosan core shell nanoparticles for the purpose of oral insulin delivery. Eur. Polym. J. 2017, 92, 294-313. [CrossRef]

20. Freitas, F.; Alves, V.D.; Reis, M.A. Advances in bacterial exopolysaccharides: From production to biotechnological applications. Trends Biotech. 2011, 29, 388-398. [CrossRef] [PubMed]

21. Gultekin, G.; Atalay-Oral, C.; Erkal, S.; Sahin, F.; Karastova, D.; Tantekin-Ersolmaz, S.B.; Guner, F.S. Fatty acid-based polyurethane films for wound dressing applications. J. Mater. Sci. Mater. Electron. 2008, 20, 421-431. [CrossRef] [PubMed]

22. Usuki, A.; Kojima, Y.; Kawasumi, M.; Okada, A.; Fukushima, Y.; Kurauchi, T.; Kamigaito, O. Synthesis of nylon 6-clay hybrid. J. Mater. Res. 1993, 8, 1179-1184. [CrossRef]

23. Yurekli, K.; Karim, A.; Amis, E.J.; Krishnamoorti, R. Influence of Layered Silicates on the Phase-Separated Morphology of PS-PVME Blends. Macromolecules 2003, 36, 7256-7267. [CrossRef]

24. Jabbari, E.; Khakpour, M. Morphology of and release behavior from porous polyurethane microspheres. Biomaterials 2000, 21, 2073-2079. [CrossRef]

25. Naheed, S.; Zuber, M.; Barikani, M.; Salman, M. Molecular engineering and morphology of polyurethane elastomers containing various molecular weight of macrodiol. Mater. Sci. Eng. B 2020, 264, 114960. [CrossRef]

26. Standard Test Method for Isocyanate Groups in Urethane Materials or Prepolymers; ASTM D2572-80; ASTM: West Conshohocken, PA, USA, 2010.

27. Yilgör, I.; Yilgor, E.; Das, S.; Wilkes, G.L. Time-dependent morphology development in segmented polyetherurea copolymers based on aromatic diisocyanates. J. Polym. Sci. Part B Polym. Phys. 2009, 47, 471-483. [CrossRef]

28. Hsu, S.-H.; Tseng, H.-J.; Lin, Y.-C. The biocompatibility and antibacterial properties of waterborne polyurethane-silver nanocomposites. Biomaterials 2010, 31, 6796-6808. [CrossRef]

29. Yilgor, I.; Yilgor, E.; Guler, I.G.; Ward, T.C.; Wilkes, G.L. FTIR investigation of the influence of diisocyanate symmetry on the morphology development in model segmented polyurethanes. Polymer 2006, 47, 4105-4114. [CrossRef]

30. Naz, F.; Zuber, M.; Zia, K.M.; Salman, M.; Chakraborty, J.; Nath, I.; Verpoort, F. Synthesis and characterization of chitosan-based waterborne polyurethane for textile finishes. Carbohydr. Polym. 2018, 200, 54-62. [CrossRef] 
31. Tabasum, S.; Zuber, M.; Jamil, T.; Shahid, M.; Hussain, R. Antimicrobial and pilling evaluation of the modified cellulosic fabrics using polyurethane acrylate copolymers. Int. J. Biol. Macromol. 2013, 56, 99-105. [CrossRef]

32. Barrioni, B.R.; de Carvalho, S.M.; Oréfice, R.L.; de Oliveira, A.A.R.; Pereira, M.D.M. Synthesis and characterization of biodegradable polyurethane films based on HDI with hydrolyzable crosslinked bonds and a homogeneous structure for biomedical applications. Mater. Sci. Eng. C 2015, 52, 22-30. [CrossRef]

33. Azzam, R.A.; Mohamed, S.K.; Tol, R.; Everaert, V.; Reynaers, H.; Goderis, B. Synthesis and thermo-mechanical characterization of high performance polyurethane elastomers based on heterocyclic and aromatic diamine chain extenders. Polym. Degrad. Stab. 2007, 92, 1316-1325. [CrossRef]

34. Malakpour, S.E.; Rostamizadeh, H. Synthesis of novel polyurethanes with Fluorescein Linkages. Iran. Polym. J. 1999, 8, 099V.

35. Travinskaya, T.V.; Brykova, A.N.; Savelyev, Y.V.; Babkina, N.V.; Shtompel, V.I. (Bio) degradable ionomeric polyurethanes based on xanthan: Synthesis, properties, and structure. Inter. J. Polym Sci. 2017, 103, 903-908. [CrossRef]

36. Chen, M.; Zhou, D.-L.; Chen, Y.; Zhu, P.-X. Analyses of structures for a synthetic leather made of polyurethane and microfiber. J. Appl. Polym. Sci. 2006, 103, 903-908. [CrossRef]

37. Naheed, S.; Zuber, M.; Salman, M.; Rasool, N.; Siddique, Z.; Shaik, M.; Sharaf, M.; Abdelgawad, A.; Sekou, D.; Awwad, E. Impact of Macrodiols on the Morphological Behavior of H12MDI/HDO-Based Polyurethane Elastomer. Polymers 2021, 13, 2060. [CrossRef]

38. Yang, C.-H.; Liu, F.-J.; Liu, Y.-P.; Liao, W.-T. Hybrids of colloidal silica and waterborne polyurethane. J. Colloid Interface Sci. 2006, 302, 123-132. [CrossRef]

39. da Silva, V.D.; dos Santos, L.M.; Subda, S.M.; Ligabue, R.; Seferin, M.; Carone, C.L.P.; Einloft, S. Synthesis and characterization of polyurethane/titanium dioxide nanocomposites obtained by in situ polymerization. Polym. Bull. 2013, 70, 1819-1833. [CrossRef]

40. Asensio, M.; Costa, V.; Nohales, A.; Bianchi, O.; Gómez, A.C.M. Tunable Structure and Properties of Segmented Thermoplastic Polyurethanes as a Function of Flexible Segment. Polymers 2019, 11, 1910. [CrossRef]

41. Naheed, S.; Zuber, M.; Barikani, M. Synthesis and thermo-mechanical investigation of macrodiol-based shape memory polyurethane elastomers. Int. J. Mater. Res. 2017, 108, 515-522. [CrossRef] 